\title{
STRUCTURES OF AUTOMATIC SYSTEMS WITH UNSTABLE PARAMETERS
}

\author{
Anatoly Potapov ${ }^{\mathrm{a}, \mathrm{b}}$, Sergey Stazhkov ${ }^{\mathrm{a}}$, Alexey Gradovtsev ${ }^{\mathrm{b}}$, \\ Igor Dalyaev ${ }^{\mathrm{a}, \mathrm{b}}$, Mikhail Ohochinsky ${ }^{\mathrm{a}}$
}

\author{
${ }^{a}$ The Baltic state technical university ("VOENMEH") of D.F.Ustinov, 1-st Krasnoarmejskaya 1, \\ Saint-Petersburg, 190005, Russia \\ ${ }^{b}$ Russian state scientific center for robotics and technical cybernetics (RTC), Tikhorecky prospect 21, \\ Saint-Petersburg, 194064, Russia
}

\begin{abstract}
All real automatic systems are nonlinear, non-stationary, with unstable parameters. The problem of the automated design of such systems with a high order (from the 4th above) has "narrow" places. The main thing is how to construct multidimensional quasi optimal "desirable" structure, with simple means, meeting contradictory requirements.

It is offered to apply model management in the form of the standard rated characteristic equations with the maximum degree of stability (SRCE-MDS). The algorithm of parametrical control which is passing to the system of the nonlinear algebraic equations decision is it is described and reasonable in this article. The control example shows how it works. Big stability of system characteristics at variations of parameters at control on SRCE-MDS is shown considerably.

By this way we can construct multidimensional quasi optimal "desirable" structure. The other way is to use adaptive control systems.
\end{abstract}

Keywords automatic systems; standart rated charecteristic equations; unstable parameters; stability; quasi optimal structures
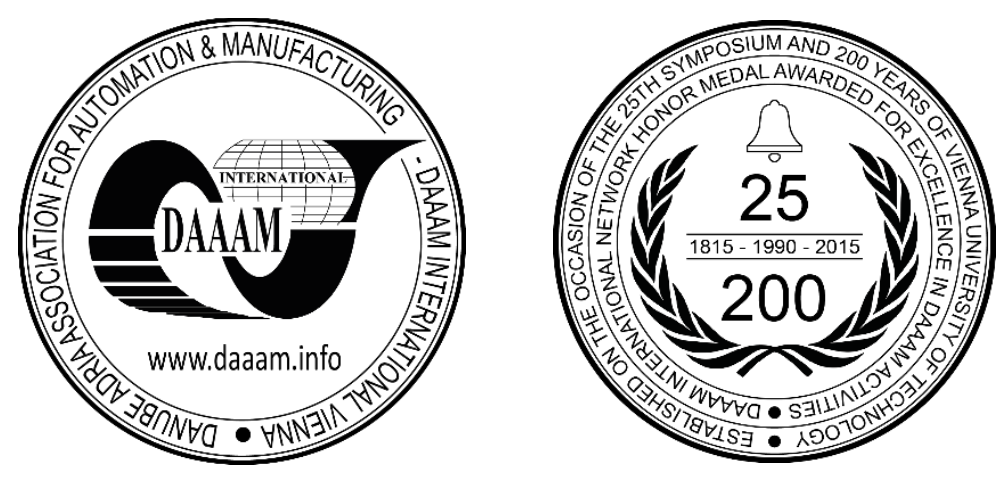

This Publication has to be referred as: Potapov, A[natoly]; Stazhkov, S[ergey]; Gradovtsev, A[lexey]; Dalyaev, I[gor] \& Ohochinsky, M[ichail] (2016). Structures of automatic systems with unstable parameters, Proceedings of the 26th DAAAM International Symposium, pp.0871-0876, B. Katalinic (Ed.), Published by DAAAM International, ISBN 9783-902734-07-5, ISSN 1726-9679, Vienna, Austria DOI: $10.2507 / 26$ th.daaam.proceedings. 121 


\section{Introduction}

Really all automatic systems (AS), including control systems and drivers are nonlinear, non-stationary or with variable parameters.

Therefore problem of creation quasi optimal multidimensional nonlinear and non-stationary mehatronics and robotic AS (MNNAS) with a high order (from the 4th above) is very actual. At machine design of MNNAS there are two "narrow" places. The first is how to formulate multidimensional optimal or quasi optimal "desirable" structure of a high order. The second one is the solution for nonlinear algebraic equations system of a high order, the majority of practical tasks unknown nonlinear conditions which really reduced to. Difficulty in formation of "desirable" structures consists, as we know, in satisfaction of contradictory requirements: ensuring the maximum speed and the maximum accuracy at set (or minimum) time of regulation and reregulation (on jump); the maximum stocks of stability and stability of characteristics at considerable variations of parameters MNNAS; not full management of situation at full providing "desirable" characteristics, etc.

\section{Modal management method}

The most widespread and convenient methods at a computerization are based on modal management $[1,2]$. As it's known, modal management is an ensuring the set distribution of poles for the closed system, i.e. own values of a matrix $[\mathrm{A}-\lambda \mathrm{E}]$ will be a characteristic polynom:

$$
(\lambda)=[\mathrm{A}-\lambda \mathrm{E}]=\lambda^{\mathrm{n}}+\mathrm{A}_{\mathrm{n}-1} \lambda^{\mathrm{n}}+\ldots+\mathrm{A}_{1} \lambda+\mathrm{A}_{0}=0
$$

where $A_{i}$ - coefficients of matrix A, which is scalar function from parameters MNNAS $\left(\mathscr{x}_{i}\right)$. That's why, if

$$
\dot{\mathrm{X}}=\mathrm{AX}+\mathrm{BU}
$$

where $\mathrm{B}_{\mathrm{i}}$ - coefficients of matrix $\mathrm{B}$, which is also scalar function from $\left(\mathfrak{x}_{\mathrm{i}}\right)$, and $\mathrm{U}-$ the entrance managing director and the revolting vector, then

$$
\mathrm{A}_{\mathrm{i}}=\mathrm{A}_{\mathrm{i}}\left(\mathfrak{x}_{\mathrm{i}}\right) \text { и } \mathrm{B}_{\mathrm{i}}=\mathrm{B}_{\mathrm{i}}\left(\mathfrak{i}_{\mathrm{i}}\right)
$$

Where

$$
\dddot{x}=\left[\mathfrak{x}_{1}, \mathfrak{x}_{2}, \ldots \mathfrak{x}_{\mathrm{n}}\right]^{\mathrm{T}}
$$

It is the required correcting and adjusted vector. Problem of its synthesis is in complete or incomplete definition at "transformation" initial structure of MNNAS to the desirable. Generally the vector ' $\mathfrak{X}$ ' includes not only the correcting chains (as at modal management), but also circuit design data. Similar methods more precisely to call quasi modal. It is standard approach, but distinctions begin with a choice of desirable structure. Here prevail two methods - dominant (Chernorutsky, Shubladze, etc.) and a method of the standard equations (Ivakhnenko, Yavorsky, Grachem-Letrop, etc.). First $[1,2]$ is based, usually, on a choice of couple of complex interfaced poles defining processes in system. The second [3-6] chooses placement of all poles and actually sets the desirable characteristic equation in a form (1). Many recommendations about a choice of the standard rated characteristic equations (SRCE) are known [7-13].

\section{Structures with the maximum degree of stability}

For today the general creation technique of desirable structures in the form of SRCE and SRCE-DS is fulfilled (or SRCE-MDS) $[3,5,7]$. We will show below that it is expedient to apply structures of SRCE-DS to non-stationary MNNAS or structures with variable inertial loading or with a considerable variation of parameters.

The structure of SRCE and SRCE-DS provides a quasi-optimality both on accuracy and speed, in temporary and frequency areas [3,5-8]. The generalized method of parametrical synthesis and MNNAS control of quasi optimum quality is offered and tested [3]. Essence in the analytical and machine algebraic procedures realizing algorithm:

$$
\sum_{i=1}^{n} \sum_{j=1}^{k} F\left(a_{j}, æ_{i}\right)=\sum_{i=1}^{n}{ }^{\prime} A_{i}{ }^{\prime} K_{B}^{n-1}
$$

where $A_{i}{ }^{\prime}$ - rated coefficients SRCE; $a_{j}$ - unchangeable parameters of system; $K_{B}$ - rationing coefficient [3, 5-7]. Dependence (5) is led to system of the nonlinear algebraic equations solved by known, usually, rather simple methods.

For comparison of control on a dominant method and SRCE-DS we will use an example from E.P.Popov's textbook [1, page 186-188] where G.S.Chernorutsky's method [2] for the solution of modal tasks is recommended by a state space method. The scheme of system is given in figure 1 . Basic data: $\mathrm{Ky}=26, \mathrm{Kd}=0,092 \mathrm{Vs}$ and $\mathrm{TM}=1,53 \mathrm{~s}$. To define $K_{u}$, Koc, Ty and Toc, providing time of regulation of $\mathrm{t}_{2}<0,8 \mathrm{~s}$ and fluctuations $\mu<1,57$. Roots are chosen: 


$$
\lambda_{1,2}=-5 \pm \mathrm{j} 7,8 ; \lambda_{3}=-8,0 ; \lambda_{4}=20
$$

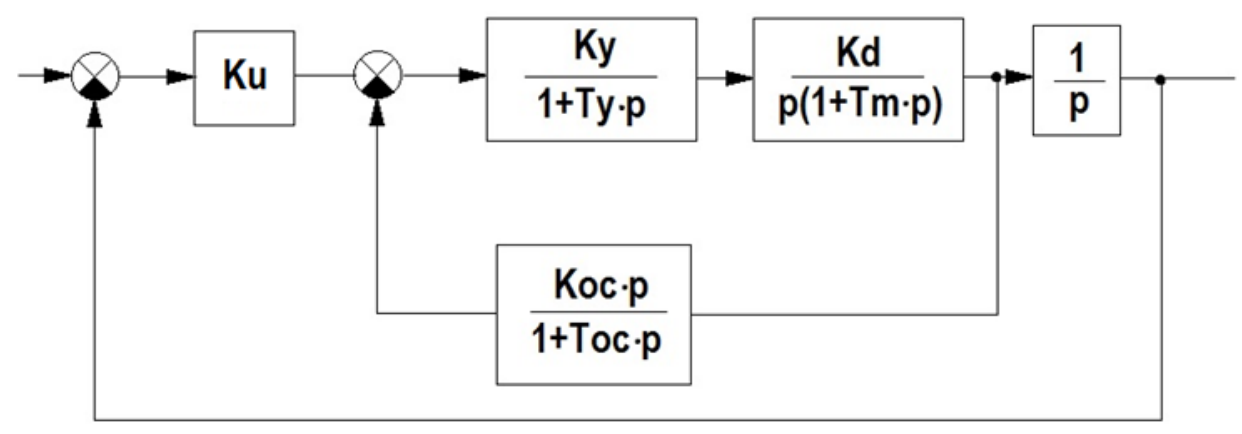

Fig. 1. System scheme

Popov-Chernorutsky $(\mathrm{PCh})$ task solution gives control $-\mathrm{Koc}=20,74 \mathrm{Vs}^{2} ; K_{u}=743,5 \mathrm{~V} ; \mathrm{Ty}=0,03 \mathrm{~s} ;$ Toc $=0,286 \mathrm{~s}$. The matrix coefficients of system leads to the characteristic equation

$$
p^{4}+A_{3} p^{3}+A_{2} p^{2}+A_{1} p+A_{0}=0
$$

where expressions for $\mathrm{A}_{\mathrm{i}}$ are given below.

We solve system on algorithm (5). From [3, 6, 7] we choose SRCE-DS3 with $A_{3}^{\prime}=3,1 ; A_{2}^{\prime}=4,467 ; A_{1}^{\prime}=3,2 ; A_{0}=1,0$; $t_{2 M}=5,5 \mathrm{~ns} ; \theta_{P O} \leq 1,2 \% ; x_{1,2}=0,775 \pm \mathrm{j} 0,83$ и $x_{3,4}=-0,775 \pm \mathrm{j} 0,4187$.

We will notice that $[5-8]$

$$
A_{i}=A_{i}{ }^{\prime} K_{B}^{n-1} \text { and } \lambda_{i}=K_{B} x_{i}
$$

We will receive settlement system in shape (5):

$$
\left[\begin{array}{c}
0,654+T_{\mathrm{OC}}^{-1}+T_{\mathrm{y}}^{-1}=A_{3}^{\prime} K_{B} \\
0,654 T_{\mathrm{OC}}^{-1}+T_{\mathrm{OC}}^{-1} T_{\mathrm{y}}^{-1}+0,654 T_{\mathrm{y}}^{-1}+0,156 T_{\mathrm{OC}}^{-1} T_{\mathrm{y}}^{-1} K_{\mathrm{OC}}=A_{2}^{\prime} K_{B}^{2} \\
0,654 T_{\mathrm{OC}}^{-1} T_{\mathrm{y}}^{-1}+0,156 T_{\mathrm{y}}^{-1} K_{u}=A_{1}^{\prime} K_{B}^{3} ; 0,156 T_{\mathrm{OC}}^{-1} T_{\mathrm{y}}^{-1} K_{u}=A_{0}^{\prime} K_{B}^{4}
\end{array}\right.
$$

Improving the position accuracy we will accept $K_{i}>800$ and from rough estimations $-K_{B}=15,0 \mathrm{c}^{-1}$. The graphic-analytical simple decision of system (8) gives control: Koc $=25,87 \mathrm{Vs}^{2} ; K_{u}=1665 \mathrm{~V}$; Ту $=0,02425 \mathrm{~s}$ и Тос $=0,2125 \mathrm{~s}$. Because of simplicity of a task the machine decision isn't required. As a result we have two options of the PCh and DS control:

$\mathrm{PCh}-p^{4}+37,48 p^{3}+5,177 \cdot 10^{2} p^{2}+3,94 \cdot 10^{3} p+1,345 \cdot 10^{4}=0$;

$\mathrm{DS}-p^{4}+46,5 p^{3}+1,005 \cdot 10^{2} p^{2}+1,08 \cdot 10^{4} p+5,0625 \cdot 10^{4}=0$.

Reaction to jump: PCh $-t_{2}=0,48 \mathrm{~s} ; \Theta_{P O}=3,8 \% ; \mathrm{m}=1,0 . \mathrm{DS}-t_{2}=0,36 \mathrm{~s} ; \Theta_{P O}=1,2 \% ; \mathrm{m}=1,0$. DS gives a prize on time of $25 \%$, reregulation $-3,16$ times and on accuracy by 3,75 times.

At variations of parameters, by a frequency coefficients technique rate $Z_{i}[3,5-7]$, where $Z_{i}=A_{u i}^{\prime} / A_{i}{ }^{\prime}$, where $A_{u i}^{\prime}-$ the changed equation coefficient (7).

Coefficients $Z_{i}$ are set on experimental data.

With $z_{1}=z_{2}=z_{3}=0,5, \mathrm{PCh}-t_{2}=0,444 \mathrm{~s} ; \theta_{P O}=4,3 \% ; \mathrm{m}=2 ; \mathrm{DS}-t_{2}=0,326 \mathrm{~s} ; \theta_{P O}=2,7 \% ; \mathrm{m}=1$.

With $z_{1}=z_{3}=0,5, z_{2}=0,6, \mathrm{PCh}-t_{2}=1,28 \mathrm{~s} ; \theta_{P O}=49 \% ; \mathrm{m}=3 ; \mathrm{DS}-t_{2}=0,664 \mathrm{~s} ; \theta_{P O}=44 \% ; \mathrm{m}=2$.

Results are obvious, but we will notice that at structure parameter variations of PCh don't lose stability as many known structures, the GL type (Grekhem-Lotrop) or B (Battervord), created for "exact" control.

By a Z-technique the following dependences are received on the personal computer for $\mathrm{n}=4-8$ :

$t_{2 M}=f\left(z_{i}\right) ; \theta_{P O}=f\left(z_{i}\right) ; \Delta L=f\left(z_{i}\right) ; \mu=f\left(z_{i}\right) ; M_{n-1}=f\left(z_{i}\right) ;$

$C_{1}=f\left(z_{i}\right) ; B_{1}=f\left(z_{i}\right) ; A_{i}^{\prime}=f\left(z_{i}\right)$.

with $x_{i}=-C_{i} \pm j B_{i} ; x_{j}=-C_{i}$.

Here $\Delta L$ and $\mu$ - stocks on amplitude and a phase; $M_{n-1}-$ penultimate gurviyets determinant. 
Results for $n=4$ are partially given in tables 1-4 and graphically in figures 2 and 3. From tables it is visible that GL and $B$ can lose stability at certain modes.

\begin{tabular}{lllllllllllllllll}
\hline$Z_{1,2,3}$ & $A_{3}^{\prime}$ & $A_{2}^{\prime}$ & $A_{1}^{\prime}$ & $C_{1}$ & $\beta_{1}$ & $C_{2}$ & $\beta_{2}$ & $C_{3}$ & $C_{4}$ & $\theta, \%$ & $t_{2}, n s$ & $\Delta \mathrm{L}, \mathrm{dB}$ & $\mu,{ }^{\circ}$ & $\mathrm{H}$ \\
\hline 0.60 & 1.80 & 2.55 & 1.80 & -0.71 & 0.71 & -0.20 & 0.98 & - & - & 40.86 & 15.12 & 3.80 & 44 & 1.8 \\
0.65 & 1.95 & 2.76 & 1.95 & -0.70 & 0.71 & -0.27 & 0.96 & - & - & 32.31 & 9.74 & 4.90 & 47 & 2.9 \\
0.70 & 2.10 & 2.98 & 2.10 & -0.70 & 0.71 & -0.35 & 0.93 & - & - & - & - & 25.40 & 9.61 & 5.10 & 51 & 4.3 \\
0.78 & 2.25 & 3.19 & 2.25 & -0.71 & 0.71 & -0.42 & 0.91 & - & - & 19.79 & 7.19 & 6.77 & 53 & 6.0 \\
0.80 & 2.40 & 3.40 & 2.40 & -0.70 & 0.71 & -0.50 & 0.87 & - & - & 15.22 & 7.34 & 7.60 & 56 & 8.0 \\
0.85 & 2.55 & 3.61 & 2.55 & -0.70 & 0.72 & -0.58 & 0.81 & - & - & - & 11.48 & 7.43 & 8.40 & 58 & 10.5 \\
0.90 & 2.70 & 3.83 & 2.70 & -0.70 & 0.76 & -0.65 & 0.71 & - & - & 8.43 & 7.41 & 9.00 & 59 & 13.3 \\
0.95 & 2.85 & 4.04 & 2.85 & -0.75 & 0.75 & -0.67 & 0.66 & - & - & 5.92 & 7.15 & 9.65 & 61 & 16.6 \\
$\mathbf{1 . 0 0}$ & $\mathbf{3 . 0 0}$ & $\mathbf{4 . 2 5}$ & $\mathbf{3 . 0 0}$ & $\mathbf{- 0 . 7 5}$ & $\mathbf{0 . 6 6}$ & $\mathbf{- 0 . 7 5}$ & $\mathbf{0 . 6 6}$ & - & - & - & $\mathbf{3 . 8 8}$ & $\mathbf{5 . 0 2}$ & $\mathbf{1 0 . 3}$ & $\mathbf{6 3}$ & $\mathbf{2 0 . 3}$ \\
1.05 & 3.15 & 4.46 & 3.15 & -0.86 & 0.52 & -0.72 & 0.69 & - & - & 2.24 & 5.34 & 10.8 & 64 & 24.4 \\
1.10 & 3.30 & 4.68 & 3.30 & -0.93 & 0.36 & -0.71 & 0.70 & - & - & 0.97 & 5.70 & 11.3 & 65 & 29.1 \\
1.20 & 3.60 & 5.10 & 3.60 & -1.51 & - & -0.71 & 0.70 & -0.66 & - & 0 & 6.55 & 12.3 & 67 & 40.2 \\
1.30 & 3.90 & 5.53 & 3.90 & -1.97 & - & -0.71 & 0.70 & -0.71 & - & 0 & 7.59 & 13.0 & 69 & 53.6 \\
\hline
\end{tabular}

Table 1. SRCE-DS_1

\begin{tabular}{lccccccccccccccc}
\hline$Z_{1,2,3}$ & $A_{3}^{\prime}$ & $A_{2}^{\prime}$ & $A_{1}^{\prime}$ & $C_{1}$ & $\beta_{1}$ & $C_{2}$ & $\beta_{2}$ & $C_{3}$ & $C_{4}$ & $\theta, \%$ & $t_{2}, n s$ & $\Delta \mathrm{L}, \mathrm{dB}$ & $\mu,{ }^{\circ}$ & $\mathrm{H}$ \\
\hline 0.60 & 2.4 & 3.6 & 2.4 & -0.74 & 1.04 & -0.46 & 0.64 & - & - & 14.57 & 7.84 & 8.35 & 55 & 9.2 \\
0.65 & 2.6 & 3.9 & 2.6 & -0.83 & 1.04 & -0.47 & 0.59 & - & - & 10.41 & 8.05 & 9.22 & 57 & 12.8 \\
0.70 & 2.8 & 4.2 & 2.8 & -0.92 & 1.03 & -0.48 & 0.54 & - & - & 7.28 & 8.04 & 10.0 & 60 & 17.2 \\
0.78 & 3.0 & 4.5 & 3.0 & -1.00 & 1.00 & -0.50 & 0.50 & - & - & 4.89 & 5.16 & 11.0 & 61 & 22.5 \\
0.80 & 3.2 & 4.8 & 3.2 & -1.08 & 0.95 & -0.52 & 0.46 & - & - & 3.05 & 5.58 & 11.6 & 63 & 28.7 \\
0.85 & 3.4 & 5.1 & 3.4 & -1.15 & 0.88 & -0.55 & 0.42 & - & - & 1.67 & 6.05 & 12.2 & 65 & 35.8 \\
0.90 & 3.6 & 5.4 & 3.6 & -1.21 & 0.77 & -0.59 & 0.37 & - & - & 0.70 & 6.57 & 13.0 & 66 & 44.1 \\
0.95 & 3.8 & 5.7 & 3.8 & -1.26 & 0.61 & -0.64 & 0.31 & - & - & 0.14 & 7.14 & 13.5 & 67 & 53.4 \\
$\mathbf{1 . 0 0}$ & $\mathbf{4 . 0}$ & $\mathbf{6 0}$ & $\mathbf{4 . 0}$ & $\mathbf{- 1 . 0 0}$ & - & $\mathbf{- 1 . 0 0}$ & - & $\mathbf{- 1 . 0 0}$ & $\mathbf{- 1 . 0 0}$ & $\mathbf{0}$ & $\mathbf{7 . 7 6}$ & $\mathbf{1 4 . 0}$ & $\mathbf{6 9}$ & $\mathbf{6 4 . 0}$ \\
1.05 & 4.2 & 6.3 & 4.2 & -1.91 & - & -0.88 & 0.47 & -0.52 & - & 0 & 8.42 & 14.5 & 70 & 75.9 \\
1.10 & 4.4 & 6.6 & 4.4 & -2.24 & - & -0.86 & 0.52 & -0.45 & - & 0 & 9.10 & 15.0 & 71 & 89.1 \\
1.20 & 4.8 & 7.2 & 4.8 & -2.79 & - & -0.83 & 0.56 & -0.36 & - & 0 & 10.48 & 15.8 & 72 & 119.8 \\
1.30 & 5.2 & 7.8 & 5.2 & -3.27 & - & -0.81 & 0.59 & -0.31 & - & 0 & 11.81 & 16.7 & 73 & 156.8 \\
\hline
\end{tabular}

Table 2. SRCE-DS_2

\begin{tabular}{lccccccccccccccc}
\hline$Z_{1,2,3}$ & $A_{3}^{\prime}$ & $A_{2}^{\prime}$ & $A_{1}^{\prime}$ & $C_{1}$ & $\beta_{1}$ & $C_{2}$ & $\beta_{2}$ & $C_{3}$ & $C_{4}$ & $\theta, \%$ & $t_{2}, n s$ & $\Delta \mathrm{L}, \mathrm{dB}$ & $\mu,{ }^{\circ}$ & $\mathrm{H}$ \\
\hline 0.60 & 1.56 & 2.04 & 1.56 & -0.77 & 0.62 & -0.01 & 0.99 & - & - & 65.02 & 196.6 & 0.34 & 26 & 0.01 \\
0.65 & 1.69 & 2.21 & 1.69 & -0.78 & 0.63 & -0.07 & 0.99 & - & - & 53.53 & 36.90 & 1.66 & 38 & 0.60 \\
0.70 & 1.82 & 2.38 & 1.82 & -0.79 & 0.61 & -0.12 & 0.99 & - & - & 44.00 & 21.34 & 2.80 & 44 & 1.26 \\
0.78 & 1.95 & 2.55 & 1.95 & -0.80 & 0.59 & -0.17 & 0.98 & - & - & 36.03 & 15.27 & 3.80 & 48 & 2.09 \\
0.80 & 2.08 & 2.72 & 2.08 & -0.82 & 0.57 & -0.22 & 0.97 & - & - & 29.32 & 12.27 & 4.71 & 51 & 3.11 \\
0.85 & 2.21 & 2.89 & 2.21 & -0.84 & 0.54 & -0.26 & 0.96 & - & - & 23.65 & 9.54 & 5.50 & 54 & 4.35 \\
0.90 & 2.64 & 3.06 & 2.34 & -0.86 & 0.51 & -0.31 & 0.95 & - & - & 18.81 & 9.31 & 6.25 & 56 & 5.80 \\
0.95 & 2.48 & 3.23 & 2.47 & -0.89 & 0.46 & -0.35 & 0.94 & - & - & 14.69 & 6.88 & 6.95 & 58 & 7.50 \\
$\mathbf{1 . 0 0}$ & $\mathbf{2 . 6 0}$ & $\mathbf{3 . 4 0}$ & $\mathbf{2 . 6 0}$ & $\mathbf{- 0 . 9 2}$ & $\mathbf{0 . 1 6}$ & $\mathbf{- 0 . 3 8}$ & $\mathbf{0 . 9 2}$ & - & - & $\mathbf{1 1 . 1 5}$ & $\mathbf{6 . 8 7}$ & $\mathbf{7 . 5 9}$ & $\mathbf{6 0}$ & $\mathbf{9 . 4 6}$ \\
1.05 & 2.73 & 3.59 & 2.73 & -0.95 & 0.30 & -0.41 & 0.91 & - & - & 8.11 & 6.75 & 8.21 & 61 & 11.70 \\
1.10 & 2.86 & 3.74 & 2.86 & -0.99 & 0.13 & -0.44 & 0.90 & - & - & 5.50 & 6.38 & 8.74 & 63 & 14.20 \\
1.20 & 3.12 & 4.08 & 3.12 & -1.49 & - & -0.48 & 0.88 & -0.68 & - & 1.35 & 5.07 & 9.76 & 65 & 20.20 \\
1.30 & 3.38 & 4.42 & 3.38 & -1.79 & - & -0.51 & 0.86 & -0.56 & - & 0 & 5.75 & 10.60 & 67 & 27.60 \\
\hline
\end{tabular}

Table 3: SRCE-B (Battervord)

\begin{tabular}{lccccccccccccccc}
\hline$Z_{1,2,3}$ & $A_{3}^{\prime}$ & $A_{2}^{\prime}$ & $A_{1}^{\prime}$ & $C_{1}$ & $\beta_{1}$ & $C_{2}$ & $\beta_{2}$ & $C_{3}$ & $C_{4}$ & $\theta, \%$ & $t_{2}, n s$ & $\Delta \mathrm{L}, \mathrm{dB}$ & $\mu,{ }^{\circ}$ & $\mathrm{H}$ \\
\hline 0.60 & 1.26 & 2.04 & 1.62 & -0.64 & 0.61 & 0.01 & 1.13 & - & - & $\infty$ & $\infty$ & - & - & -0.05 \\
0.65 & 1.37 & 2.21 & 1.78 & -0.63 & 0.59 & -0.05 & 1.16 & - & - & 44.76 & 45.56 & 1.47 & 50 & 0.34 \\
0.70 & 1.47 & 2.38 & 1.89 & -0.63 & 0.58 & -0.11 & 1.17 & - & - & 35.68 & 20.89 & 2.98 & 52 & 0.88 \\
0.78 & 1.58 & 2.55 & 2.03 & -0.62 & 0.55 & -0.17 & 1.19 & - & - & 27.22 & 13.01 & 4.22 & 55 & 1.55 \\
0.80 & 1.68 & 2.72 & 2.16 & -0.62 & 0.53 & -0.22 & 1.21 & - & - & 20.14 & 10.01 & 5.32 & 57 & 2.38 \\
0.85 & 1.79 & 2.89 & 2.30 & -0.62 & 0.50 & -0.28 & 1.22 & - & - & 14.22 & 5.91 & 6.27 & 59 & 3.39 \\
0.90 & 1.89 & 3.06 & 2.43 & -0.62 & 0.48 & -0.33 & 1.24 & - & - & 9.28 & 5.79 & 7.15 & 60 & 4.58 \\
0.95 & 2.00 & 3.23 & 2.57 & -0.62 & 0.45 & -0.38 & 1.25 & - & - & 5.20 & 5.30 & 7.96 & 62 & 5.97 \\
$\mathbf{1 . 0 0}$ & $\mathbf{2 . 1 0}$ & $\mathbf{3 . 4 0}$ & $\mathbf{2 . 7 0}$ & $\mathbf{- 0 . 6 2}$ & $\mathbf{0 . 9 9}$ & $\mathbf{- 0 . 4 2}$ & $\mathbf{1 . 2 7}$ & - & - & $\mathbf{1 . 9 3}$ & $\mathbf{4 . 2 8}$ & $\mathbf{8 . 7 0}$ & $\mathbf{6 3}$ & $\mathbf{7 . 3 3}$ \\
1.05 & 2.21 & 3.57 & 2.84 & -0.63 & 0.38 & -0.47 & 1.27 & - & - & 0.90 & 4.62 & 9.35 & 65 & 9.40 \\
1.10 & 2.31 & 3.74 & 2.97 & -0.64 & 0.34 & -0.51 & 1.28 & - & - & 0.60 & 5.06 & 9.95 & 66 & 11.50 \\
1.20 & 2.52 & 4.08 & 3.24 & -0.66 & 0.25 & -0.60 & 1.28 & - & - & 0.26 & 6.29 & 11.10 & 68 & 16.50 \\
1.30 & 2.73 & 4.42 & 3.51 & -0.69 & 0.09 & -0.68 & 1.27 & - & - & 0 & 7.25 & 12.10 & 69 & 22.58 \\
\hline
\end{tabular}

Table 4: SRCE-GL (Grekhem-Lotrop) 


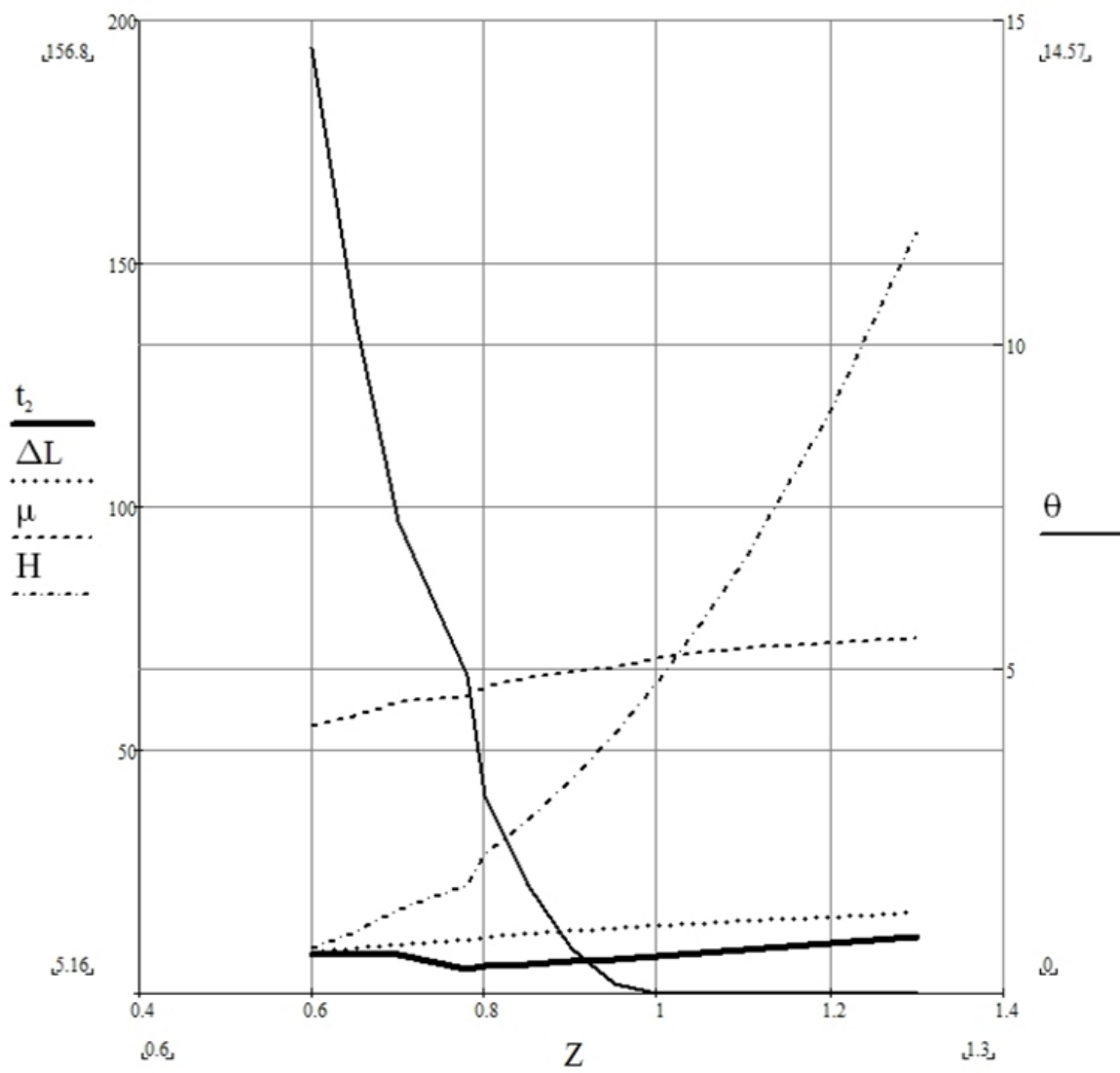

Fig. 2. SRCE-DS_2

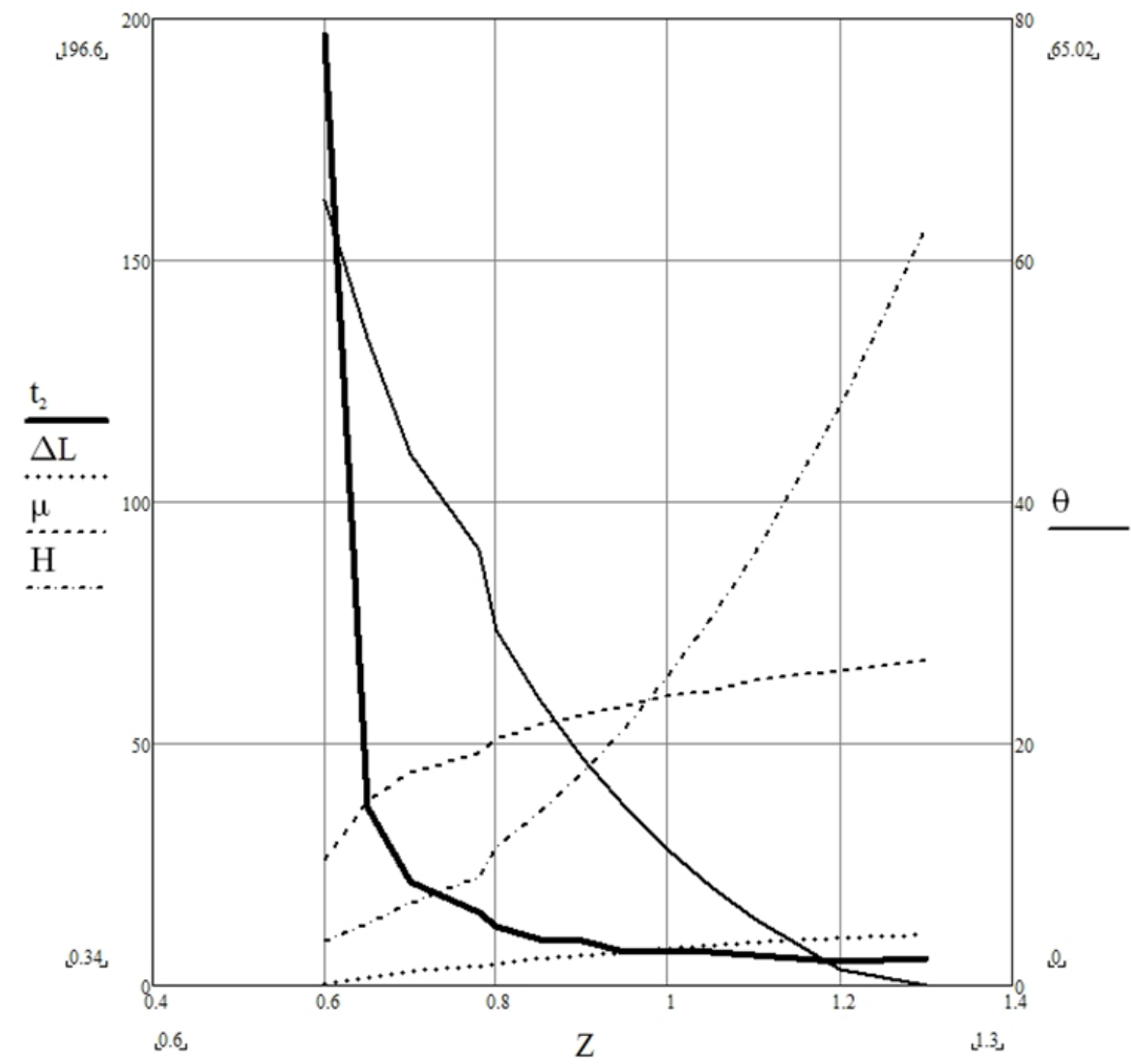

Fig. 3. SRCE-B 


\section{Conclusion}

It is possible to give schedules of some dependences, but it is possible to recommend control without any calculations. For example (figure 3) restrictions are put on $t_{2}$ and $\Theta_{P O}$. The cut-offs lines are drawn at once. Or (figure 2) restriction on operating modes at variations of parameters (i.e. admissible $z_{i}$ ). Thus, for MNNAS at unstable parameters structures of SRCE-DS are recommended [3-10]. It can be used for example in [14].

As another way we can use adaptive control systems. A key open question in adaptive estimator design is how to assure that the parameters of the proposed algorithms are converging to their almost correct solutions [15]. It will be the following step.

\section{References}

[1] Popov E.P. Theory of linear automatic control systems. In: Moscow, Nauka (Москва, Наука) 1989.

[2] Chernorucki G.S. and other. Servosystems of automatic manipulators. In: Moscow, Nauka (Москва, Наука) 1987.

[3] Potapov A, Sherba V, Potapov A. Parametric synthesis and adjustment of dynamic quasioptimal quality systems on the basis of model normalized structures of characteristic equation having the maximal degree of stability. In: Tenth World Congress of the Theory of Machines and Mechanisms, Proceedings, v.5, Finland, 1999, p. 2009-2013.

[4] Ivahnenko A.G. Elecric-automation. In: Kiev, Gostehizdat (Гостехиздат), 1957.

[5] Javorsky V.N. i dr. Invariant servo drives design. In: Moscow, High School (Высшая школа), 1964.

[6] Potapov A.A. Actuators adjustment for a maximum degree of stability. In: Robotic automation systems of nuclear power. Leningrad., LDNTP, 1988.

[7] Potapov A.M. Potapov A.A. The theory and characteristics of model equations with the maximum degree of stability of the fourth order. In: Robotics and Mechatronics vol. 1, Russian Academy of Sciences (PAH), 1996.

[8] Potapov A.M., Kabikov V.V. Control systems of the longitudinal speed structures analytical formation. In: Extreme robotics conference papers v.11. (Экстремальная робототехника, труды конференции), SPbGTU, 2001.

[9] Potapov A.M. Potapov A.A. Model equation of high order with a maximum degree of stability. In: Elements and control of robotic systems for extreme environments (Элементы и системы управления робототехнических комплексов для экстремальных сред), LDNTP, 1990.

[10] Potapov A.M. Fundamentals of theory and practice of non-stationary multistage mechatronic complexes to high technology. In: Mehatronics, sutomatization and control (Мехатроника, автоматизация и управление), №6, 2003.

[11] Umez-Eronini. E. System Dynamics and Control. Pacific Grove, CA: Brooks/Cole Publishing Company, 1999.

[12] Katsuhiko Ogata. Modern Control Engineering. Fifth edition. Prentice Hall.

[13] Wang, Y.G. \& Cai, W.J. (2002). Advanced Proportional-Integral-Derivative Tuning for Integrating and Unstable Processes with Gain and Phase Margin Specifications. Industrial Engineering Chemistry Research, Vol.41, No.12, pp. 2910-2914.

[14] Migdalovici M, Vladareanu L, Baran D, Radulescu M. Stability analysis of the walking robot motion. In: Procedia computer science 65:233-240, December 2015.

[15] O.Tutsoy, S.Colak. Adaptive estimator design for unstable output error systems: A test problem and traditional system identification based analysis. In: Proceedings of the institution of mechanical engineers part 1. Journal of systems and control engineering 229(10):902-916 - November 2015. 